\title{
SFM Interim Practice Recommendations for Zika Virus Infection in Pregnancy
}

\author{
K. Aparna Sharma ${ }^{1,2}$ (1) Bimal Sahani ${ }^{1}$ T. L. N. Praveen ${ }^{1} \cdot$ Anubhuti Rana $^{1}$ • \\ K. V. Seneesh ${ }^{1} \cdot$ Supriya Gambhir $^{1} \cdot$ Vivek Krishnan $^{1} \cdot$ Vidyalekshmy $^{1}$ • \\ Meenu Batra $^{1} \cdot$ Bijoy Balakrishnan $^{1} \cdot$ Ashok Khurana $^{1}$
}

Received: 17 January 2022/ Accepted: 22 January 2022/Published online: 11 February 2022

(C) Society of Fetal Medicine 2022

\begin{abstract}
Zika virus (ZIKV) belongs to the family of flaviviruses and is transmitted by mosquitoes of the genus Aedes (A. aegypti and A. albopictus). ZIKV infection in pregnancy can have serious implications on the fetus and the neonate. Vertical transmission to the fetus can occur irrespective of symptomatic or asymptomatic infection in the pregnant woman and the risk can persist throughout pregnancy. The exact frequency of maternal-to-fetal transmission of Zika virus is difficult to determine accurately. The greatest risk of serious fetal sequelae is seen if the infection occurs within the first and second trimester. However, they can also be seen with infections in the third trimester. This document describes the presentation, fetomaternal manifestations, role of prenatal Ultrasound in diagnosis of infection, testing methods and the management in pregnancy and screening in the neonatal period. In the absence of robust evidence as to the definite effects, this document is aimed at providing practice recommendations for the management of this infection.
\end{abstract}

Keywords Zika virus · Pregnancy · Microcephaly

\begin{abstract}
About the Virus
Zika virus (ZIKV) is transmitted by mosquitoes of the genus Aedes (A. aegypti and A. albopictus). It belongs to the family of flavivirus and is closely related to other
\end{abstract}

K. Aparna Sharma

kaparnasharma@gmail.com

Society of Fetal Medicine, New Delhi, India

2 Department of Obstetrics and Gynaecology, All India Institute of Medical Sciences, New Delhi 110029, India flaviviruses including dengue virus, Japanese encephalitis, yellow fever virus and West Nile virus. Outbreaks of infection with Zika virus have occurred in Africa, South East Asia, Pacific islands, America, and the Caribbean $[1,2]$. Acute onset of low-grade fever with maculopapular pruritic rash, arthralgia (particularly of small joints of hands and feet), or conjunctivitis (non-purulent) are the common clinical features of Zika virus infection. These are reported to occur in only about 20 percent of infected individuals. Zika virus may be transmitted to humans via the infected mosquito through a bite, maternal to fetal transmission, sexual transmission (including vaginal, oral and/or anal sex), transfusion of blood and/or blood products, organ transplantation and laboratory exposure [3].

\section{Zika Virus Outbreaks in India}

Around January 2017, three confirmed cases were reported and the first outbreak was from Ahmedabad in the state of Gujarat. A second outbreak was reported in Tamil Nadu. This was followed by 94 confirmed cases in the state of Rajasthan in 2018 [4], which also included 22 pregnant women. There have been recent outbreaks in different parts of India. There were 37 confirmed cases of Zika virus infection in Kerala during July 2021 and 89 cases in Kanpur in November 2021 [5].

\section{Clinical Manifestations in the Mother}

Pregnant women have been reported to develop symptoms in $17 \%$ to as high as $56 \%$ of cases of ZIKV infection [6]. The incubation period is $2-14$ days. The common symptoms are acute onset of low grade fever $\left(37.8\right.$ to $\left.38.5^{\circ} \mathrm{C}\right)$, 
pruritic rash (erythematous macules and papules on the face, trunk, extremities, palms, and soles), arthralgia (notably in the small joints of the hands and feet), and conjunctivitis (non-purulent). The less common symptoms include myalgia, headache, retro-orbital pain and vomiting. These generally resolve within 2-7 days and the infection usually has a mild course. When two or more of the symptoms are present as depicted in Table 1, then clinical illness consistent with Zika virus disease is said to be present.

There is immunity to re-infection following primary infection. Prior dengue infection may be protective against symptomatic infection with Zika virus.

\section{Effect of Infection with Zika Virus on the Fetus and Adverse Pregnancy Outcomes}

\section{Risk of Vertical Transmission}

Vertical transmission to the fetus can occur irrespective of symptomatic or asymptomatic infection in the pregnant woman and the risk can persist throughout pregnancy. The exact frequency of maternal-to-fetal transmission of Zika virus is difficult to determine accurately.

The greatest risk of serious fetal sequelae is seen if the infection occurs within the first and second trimester. However, they can also be seen with infections in the third trimester.

In a cohort study of 130 infants whose mothers developed symptomatic ZIKV in pregnancy which was confirmed with PCR testing, the vertical transmission rate was 65 percent [8]. Other reports have suggested lower rates. The rate was 26 percent $(76 / 291)$ in a prospective cohort study from French Guiana [9].

\section{Consequences of Vertical Transmission}

The overall risk of any abnormality or birth defect varies widely (6 to 8 percent in studies in the United States versus over 40 percent in a Brazilian study) among fetuses and infants of women with ZIKV infection during pregnancy [10-12].

Beyond birth defects, there also have been reports of fetal loss (miscarriage, stillbirth), hydrops fetalis, fetal growth restriction, neurologic and positional abnormalities, and impaired neurodevelopment.

\section{Spectrum of Abnormalities}

\section{CNS Manifestations}

The virus shows neurotropism in-vivo and in-vitro. There are stages of affection where the infection from the mother leads to consequent infection of the placenta and the fetus. etal brain gets preferentially affected involving the neuronal progenitor cells which leads to disruption of neuronal growth, proliferation, migration, and differentiation. This leads to impaired brain development. This reflects as congenital microcephaly, Guillain Barré syndrome, myelitis, and meningoencephalitis.

The ultrasound manifestations in the fetus can appear as early as two weeks. However, these are more prominent in the second and third trimester. The three most common findings detected on a prenatal ultrasound include microcephaly, ventriculomegaly and intracranial calcifications, especially along the grey matter-white matter junction rather than punctate calcifications as seen with other congenital infections.

Microcephaly When the fetal head is significantly smaller than expected for gestational age it is labeled as

Table 1 WHO Case definitions of clinical illness consistent with Zika virus disease [7]

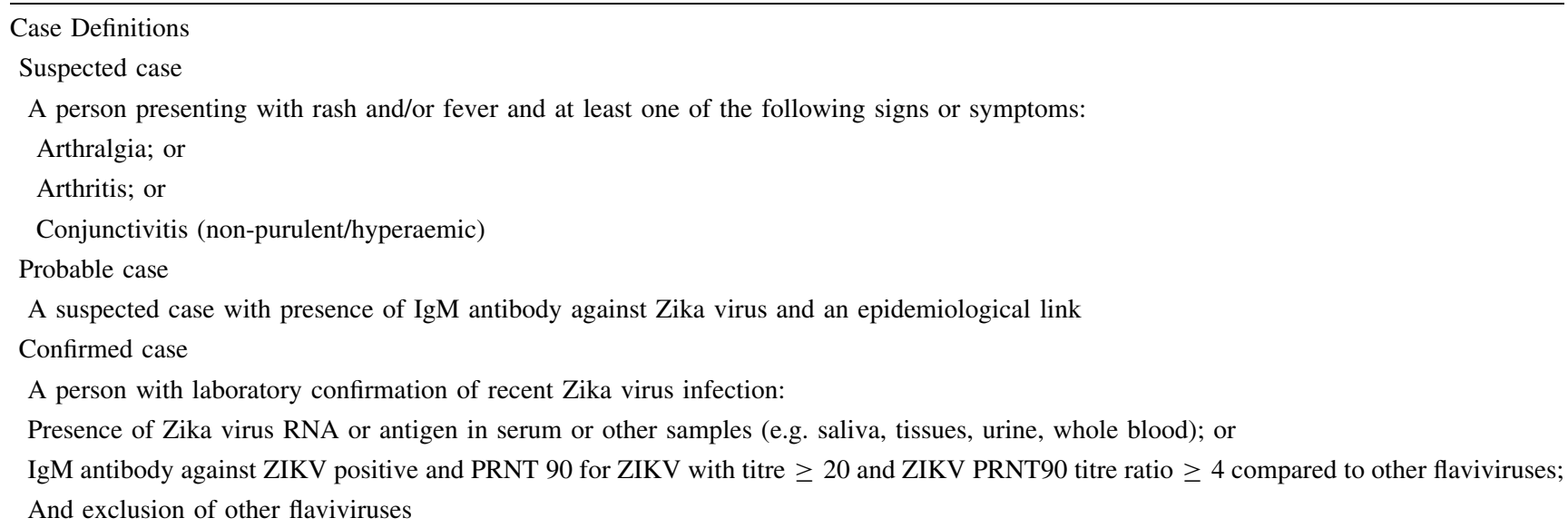


microcephaly. It is a sign of underlying pathology. The overall frequency of microcephaly following in utero Zika virus exposure is $5-7 \%$ and it can be primary (noted at birth) or secondary (developing in the first months of life) [13].

It generally reflects that the infection occurred early in pregnancy. Both disproportionate and proportionate microcephaly can be observed suggesting that it can affect fetal growth in addition to its destructive effect on the fetal brain. It can be detected as early as 18 weeks of gestation. Irrespective of which criteria is used to define microcephaly, it is important to note that the head circumference should be disproportionately smaller in comparison to abdominal circumference and femur length and not explained by other etiologies or congenital malformations (Table 2). Zika virus related microcephaly should be suspected if microcephaly is associated with a molecular or epidemiological link to Zika virus in the absence of other conditions known to cause microcephaly.

A molecular or epidemiological link with Zika virus is defined as:

- The pregnant woman is a confirmed case of Zika virus disease; or

- The pregnant woman had unprotected sexual contact with a confirmed case, or a history of symptoms or signs consistent with Zika virus infection and residing/traveling in an area with ongoing Zika virus transmission during her pregnancy; or

- Presence of Zika virus in amniotic fluid (identified through amniocentesis and RT-PCR assay); or

- Presence of Zika virus in fetal brain tissue (identified post-mortem through RT-PCR assay)

Regardless of the criteria used, for in utero diagnosis of Zika virus-induced microcephaly, the occipitofrontal circumference should be disproportionately small in comparison with the abdominal circumference and femur length and not explained by other etiologies or congenital disorders. If the occipitofrontal circumference is $\geq$ 3rd percentile but is notably disproportionately small compared with the abdominal circumference and fetal length or if central nervous system abnormalities are noted, additional evaluation for ZIKV infection may be appropriate.

The various other features that can be found are [17]:

Irregular head shape including a sloping/slanted forehead, cystic lesions, intraventricular adhesions, callosal dysgenesis or agenesis, cerebellar hypoplasia or vermian dysgenesis, enlarged cisterna magna, abnormal cortical development with reduced amount of brain parenchyma, arthrogryposis, club foot and microphthalmia.

The reported sensitivity of ultrasound is $22 \%$ and specificity $98 \%$ for detection of infection [18].

In Zika virus specific associated neuroanatomic anomalies such as diffuse calcification of subcortical parenchyma and thalamus, ventriculomegaly, lissencephaly, and pachygyria have been distinctively highlighted [19], along with a constellation of particular neuro- pathological findings such as: gliosis, abnormal neuronal migration, dysmaturation of nerve cells, hypomyelination, loss of descending axons, and spinal motor neurons.

The principal clinical features of congenital Zika syndrome $(\mathrm{CZS})$ in the newborn include microcephaly, facial disproportion, hypertonia/spasticity, hyperreflexia, seizures, irritability, arthrogryposis, ocular abnormalities and sensorineural hearing loss. The unique features of CZS that are rarely seen with other congenital infections are:

- Severe microcephaly with partially collapsed skull

- Thin cerebral cortices with subcortical calcifications

- Macular scarring and focal pigmentary retinal mottling

- Congenital contractures

- Marked early hypotonia

\section{Fetal Growth Abnormalities}

Infection with Zika virus can result in symmetric or asymmetric fetal growth restriction [20].

In a United States cohort of women with antenatal ZIKV infection, 11.2 percent were small for gestational age, compared with 5.8 percent of controls.

Table 2 Various standard definitions of microcephaly

\begin{tabular}{ll}
\hline Recommendation by & Definition of microcephaly \\
\hline WHO [14] & $\begin{array}{c}\text { Occipitofrontal circumference (head circumference) greater than } 2 \text { SD below the mean or less than the } \\
\text { 3rd percentile based on standard growth charts for sex, age, and gestational age at birth (Postnatal) }\end{array}$ \\
$\begin{array}{l}\text { Occipitofrontal circumference below the 3rd percentile or greater than } 2 \text { SD below the mean. (Postnatal) } \\
\begin{array}{l}\text { Society of Maternal-Fetal } \\
\text { Medicine [16] }\end{array}\end{array}$ & $\begin{array}{l}\text { Head circumference equal to or greater than 3 SD below the mean for gestational age } \\
\text { Pathologic microcephaly when head circumference is greater than 5 SD below the mean for gestational age }\end{array}$ \\
\hline
\end{tabular}




\section{Cardiac Anomalies}

Zika outbreak in the Brazilian study reported that $11 \%$ (13/ 120) of fetuses had non-severe cardiac defects (ASD, VSD, PDA) [21]. The frequency was increased in babies whose mothers developed a rash in the second half of pregnancy or those who were noted to have abnormal postnatal central nervous system imaging and in those who were preterm.

\section{Trimester Specific Risks of Affection}

Infection with Zika virus can result in fetal loss (miscarriage, stillbirth) and hydrops fetalis. Placental insufficiency from injury or infarction is the possible mechanism for fetal loss in the latter half of pregnancy (Table 3).

\section{Diagnosis of Infection}

The approach to diagnosis is different in pregnant women due to longer persistence in the maternal serum.

All pregnant women should be verbally screened for any possible exposure to Zika virus at the initial antenatal visit. In case the pregnant woman resides in the endemic region or there is any history of travel related exposure, the pregnant woman should be screened verbally for any possible symptoms of the infection.

\section{Laboratory Diagnosis of Maternal Infection}

\section{Indications}

Testing for Zika virus should be done for:

- Every symptomatic pregnant woman with possible ZIKV exposure

- Asymptomatic pregnant women with ongoing possible ZIKV exposure

- ZIKV-exposed pregnant women whose fetus presents with prenatal US findings consistent with congenital ZIKV infection.
- Asymptomatic pregnant women with recent possible but no ongoing exposure to ZIKV (travel history)

\section{Types of Tests}

\section{a. NAAT Test-RTPCR}

Nucleic acid detection (Zika virus RNA) by reverse transcriptase-polymerase chain reaction (RT-PCR) testing of whole blood (or serum or plasma) which targets the non-structural protein is the mainstay of diagnosis during the acute phase of infection and up to even 12 weeks of symptom onset. Standard RTPCR and quantitative RT-PCR provide a rapid, specific and sensitive method for early detection of infection. If the sample was taken later in the course of infection, a negative PCR test might not exclude infection with Zika virus as the viremia levels fall rapidly. Zika virus RNA also has been detected in urine or saliva samples.

b. Antibody test-IgM ELISA/Immunofluorescence test Later in the infection, convalescent phase ( $\geq 5$ days) can reflect as a positive serology by testing IgM antibodies (Zika virus immunoglobulin $\mathrm{M}$ ) in blood by ELISA. This, however, is not the mainstay of diagnosis as cross reactivity with other flaviviruses and false positive results are very high, thus making it extremely difficult to interpret serology in women who have resided in dengue endemic areas or have had a past infection with any flavivirus.

Interpretation of serology tests:

- If the results are positive or equivocal: Further sample may be submitted, and the pregnant woman should be referred to a fetal medicine specialist for further evaluation and follow up.

- If the result is negative: Repeat testing may be recommended a few weeks after the last possible exposure, before Zika infection can be ruled out with confidence. It may be considered to test these individuals for other potential causes of their symptoms such as dengue, chikungunya and malaria

Table 3 Effect on the fetus by Zika virus infection in various trimesters [22]

\begin{tabular}{llll}
\hline Effect on fetus & $\begin{array}{l}\text { Percentage prevalence of defect if } \\
\text { infection in first trimester }(\%)\end{array}$ & $\begin{array}{l}\text { Percentage prevalence of defect if } \\
\text { infection in second trimester }(\%)\end{array}$ & $\begin{array}{l}\text { Percentage prevalence of defect if } \\
\text { infection in third trimester }(\%)\end{array}$ \\
\hline $\begin{array}{l}\text { Microcephaly } \\
\text { Neurologic and }\end{array}$ & 10 & 3 & 4 \\
$\begin{array}{l}\text { Ocular defects } \\
\text { ing }\end{array}$ & $3-4$ & $5-6$ \\
\hline
\end{tabular}


c. Plaque Reduction Neutralization Test (PRNT):

- Confirms diagnosis in inconclusive antibody testing.

- Discriminates between crossreacting antibodies in primary flavivirus infections

d. Virus Isolation

- NOT a diagnostic tool. For supplemental research studies in public health surveillance

\section{Sample Transport, Storage and Processing}

- Sample types

Primary Blood / Serum (5 ml), EDTA samples (5 ml), CSF(1 ml): Suspected GBS/Myelitis.

Secondary samples Urine, Semen, Saliva (To detect carriers/Late sample collection in patients).

- Transportation and storage:

- Triple layer packaging (“Appendix 1")

- Sample collection form ("Appendix 2")

- Follow sample storage temperatures

\section{In Case of Delay}

- Keep refrigerated $\left(2-8{ }^{\circ} \mathrm{C}\right)-$ To be processed / Sent to VRDL within $48 \mathrm{~h}$.

- Keep frozen $\left(-10\right.$ to $\left.-20{ }^{\circ} \mathrm{C}\right)$ - To be processed after within 48-72 h

- Keep frozen $\left(-70{ }^{\circ} \mathrm{C}\right)$-To be processed after a 7 days. The sample can be preserved for extended periods

- Precautions

- A BSL-2 containment level is needed for suspected samples

- Consider all specimens as potentially infectious

- Gloves are MANDATORY

- Separate sample container labeled with the patient's name and identification number, the collection site, the date of collection and the time of the collection

- Do not contaminate the outside of the specimen container

- Empty vials and gloves to be packed in biohazard bags, secured and loaded to autoclave for decontamination.

- Remarks

1. The nodal laboratories for each district are decided, samples dispatched accordingly to the respective viral research and diagnostic laboratories (VRDLs)
2. NIV Pune and NCDC were identified as the Apex labs for testing the suspected Zika Viral Fever patients during the last outbreak in India.

3. The positive samples were transported to NIV, Pune for Sequencing.

\section{Ultrasound Screening for Fetal Affection}

It is recommended to perform prenatal ultrasound for screening of fetal abnormalities consistent with Zika infection for all pregnant women in whom laboratory testing (RT-PCR for Zika virus RNA or Zika virus specific IgM) is suggestive or diagnostic of possible Zika virus infection. Moreover, it is important to note that pregnant women with only history of possible exposure but without laboratory evidence of infection should only undergo routine ultrasound examination as recommended for routine antenatal evaluation. The ideal timing between exposure and first ultrasound screening and even follow up screening are not clearly known. The minimum time may be as short as two weeks in a few cases and may be seen as early as 18-20 weeks. In the majority of cases, fetal abnormalities are usually detected in the late second and early third trimesters of pregnancy despite infection in the first trimester.

Screening protocol:

- Timing of ultrasound:

- It is reasonable to perform the first ultrasound examination four weeks from the suspected exposure, followed by serial ultrasound examinations every four weeks, ensuring that at least one ultrasound is performed between 28 and 33 weeks of gestation.

- Checklist for ultrasound:

- Detailed fetal CNS examination to look for abnormalities

- Fetal growth to look for any growth restriction

- Detailed fetal echocardiography to look for any cardiac defects

- Fetal position to look for contractures and related limb abnormalities or club foot.

It must be noted that all pregnant women residing in areas with Zika virus transmission should be advised to continue their scheduled antenatal visits in accordance with the local policy.

In case of an exposed pregnant women with no reported symptoms during travel or within 2 weeks of return or probable sexual exposure, an ultrasound for fetal growth and anatomy may be done. If this is abnormal, she should be referred to a fetal medicine specialist for review. 
However, if the baseline ultrasound is normal, a repeat ultrasound in the third trimester may be considered.

\section{Management in Pregnancy}

\section{Maternal Management}

Currently, there is no specific management for infection with Zika virus. The woman should be advised rest and symptomatic treatment. She should drink fluids to prevent dehydration and paracetamol can be administered to relieve fever and pain. Dengue infection should be ruled out before prescribing aspirin and other (NSAIDs) and should be avoided until then to reduce the risk of hemorrhage.

\section{Monitoring for Fetal Affection}

a. Ultrasound

Prenatal ultrasound should be performed to detect fetal abnormalities as enlisted above. The timing, the screening protocol as discussed above should be followed. In case of fetal growth restriction or microcephaly, serial follow up ultrasound should be based upon each clinical scenario.

b. Invasive testing

The exact indications, appropriate gestational age for the test and the interpretation of test results of amniocentesis are quite uncertain [23]. The sensitivity and specificity are also not exactly known. It may be performed 6-8 weeks after maternal infections and the highest sensitivity may be around 21 weeks. In addition, Zika virus RT-PCR positivity in amniotic fluid is diagnostic of fetal viral exposure but not predictive of outcome especially if the test was performed because of maternal laboratory testing and the fetus appears normal on ultrasound. The diagnostic accuracy of RTPCR test in identifying congenital infection, and to what extent a positive test can predict subsequent fetal malformations is currently not known. Hence, the decision should be based on individual circumstances or clinical scenarios.

Amniocentesis is offered to pregnant women:

- Who have ultrasound findings suggestive of congenital Zika virus syndrome

- And/or positive or inconclusive maternal laboratory test results for Zika virus infection, when this information will impact decisions about pregnancy termination or ongoing pregnancy and delivery management.

Interpretation of amniotic fluid results:
- Positive rRT-PCR of amniotic fluid: It is considered diagnostic of fetal infection.

- Negative rRT-PCR of amniotic fluid: It does not rule out congenital infection as the virus may be detected transiently only.

\section{Antepartum Fetal Monitoring}

As there is an increased risk of adverse pregnancy outcome due to fetal growth restriction or even hydrops fetalis, antepartum fetal monitoring may be performed based on the ultrasound affection of fetus. In case of abnormal results, the management should be based on the routine obstetric policies.

\section{Decision for Termination of Pregnancy}

Extensive counseling should be offered to any pregnant woman who is detected positive for Zika virus infection in order to make an informed decision on termination of pregnancy, provided it is within the stipulations laid down under Medical Termination of Pregnancy Act.

Pregnant mothers, positive for Zika virus disease and beyond the period of gestation permissible by the MTP Act should be followed up for ultrasonographic evidence of microcephaly or other evidence of Zika virus affection as per the ultrasound protocol discussed above and counseled accordingly.

\section{Management of Labour, Delivery and Postpartum Period}

- Routine obstetric standards and policies guide and determine the timing and route of delivery.

- No evidence of maternal risk from placement of neuraxial anesthesia in women with uncomplicated active infection (no Guillain Barré syndrome).

- In women with positive or inconclusive Zika virus testing results, histopathology (HPE) of the placenta and umbilical cord, Zika virus immunohistochemical (IHC) staining on fixed tissue or Zika virus RNA testing (via RTPCR) on fixed and frozen tissue can be done to document fetal infection.

- RTPCR and HPE with IHC should also be performed on fetal tissues including the umbilical cord and placenta in cases of fetal loss or stillbirths [24].

- Women should continue to breastfeed as the small potential risk of Zika virus transmission through breast milk is outweighed by the known benefits of breastfeeding. 


\section{Post-natal Presentation}

The majority of fetal or neonatal manifestations are identified postnatally. Ocular abnormalities are common including, pigmentary maculopathy, circumscribed chorioretinal atrophy, optic nerve abnormalities, microcornea, microphthalmia, cataracts, retinal dysplasia. Hearing loss has been reported in $7.1 \%$ in a large series $(5 / 70)$. Neurologic and positional abnormalities can manifest in the form of hypertonia, hypotonia, spasticity and hyperreflexia [25].

\section{Strategies for Surveillance and Prevention}

\section{Primary Prevention}

- Adhere to mosquito protective measures

- Adhere to measures (abstinence or condoms) throughout pregnancy to protect against sexual transmission if a partner (male or female) has traveled to or lives in an area with a risk of Zika virus infection

- Adhere to standard infection precautions

- Guidance for couples planning pregnancy For couples residing in areas with active Zika virus transmission.

- Inform about the risks of transmission

- Consequences

- Possibility of delaying pregnancy

- For couples with a history of Zika infection:

- If the male partner is positive wait at least six months from symptom onset before attempting conception

- Of the female partner is positive wait at least eight weeks from symptom onset before attempting to conceive

\section{Secondary Surveillance Plan [26, 27]}

1. All pregnant women in the defined area be under surveillance for febrile illness.

2. Testing strategies:
Testing the Mother

\begin{tabular}{|c|c|}
\hline \multirow[t]{4}{*}{ Ask about } & $\begin{array}{l}\text { Travel or residence in areas with Zika virus } \\
\text { transmission before or during the current } \\
\text { pregnancy }\end{array}$ \\
\hline & Possible sexual exposure before or during pregnancy \\
\hline & $\begin{array}{l}\text { Diagnosis of lab-confirmed infection before } \\
\text { pregnancy }\end{array}$ \\
\hline & Symptoms of Zika virus during current pregnancy \\
\hline \multirow[t]{3}{*}{$\begin{array}{l}\text { Counsel } \\
\text { regarding }\end{array}$} & $\begin{array}{l}\text { Personal protective measures against mosquito bites } \\
\text { and possible sexual transmission }\end{array}$ \\
\hline & $\begin{array}{l}\text { Environmental protective measures for reducing } \\
\text { proliferation of mosquitos }\end{array}$ \\
\hline & $\begin{array}{l}\text { Reporting signs and symptoms suggestive of Zika } \\
\text { virus infection }\end{array}$ \\
\hline \multirow[t]{4}{*}{ Whom to test } & $\begin{array}{l}\text { Every symptomatic pregnant women with possible } \\
\text { ZIKV exposure }\end{array}$ \\
\hline & $\begin{array}{l}\text { Asymptomatic pregnant women with ongoing } \\
\text { possible ZIKV exposure }\end{array}$ \\
\hline & $\begin{array}{l}\text { ZIKV exposed pregnant women whose fetus presents } \\
\text { with prenatal US findings consistent with } \\
\text { congenital ZIKV infection }\end{array}$ \\
\hline & $\begin{array}{l}\text { Asymptomatic pregnant women with recent possible } \\
\text { but not ongoing exposure to ZIKV (travel history) }\end{array}$ \\
\hline \multirow[t]{2}{*}{ Which test } & RT-PCR in acute phase in serum \\
\hline & Serology after the acute phase \\
\hline Where to test & Government approved VRDLs \\
\hline TAT of tests & $7-10$ days \\
\hline
\end{tabular}

3. All febrile cases in the defined geographic area should be in home isolation in a mosquito proofed room.

4. If mosquito proofed room is not available, LLIN bed nets to be used.

5. Persons who test positive for Zika virus disease to be in isolation in mosquito free surroundings for 14 days.

6. Men/ women who had tested positive for Zika virus disease to be counseled for safe sex practices to be followed for a period of six months 


\section{Testing the New-Born and Follow-Up}

Initial evaluation For infants born to mothers with laboratory evidence of Zika virus infection and/or infants with findings suggestive of congenital Zika infection in the setting of a maternal epidemiologic link:

1. Thorough physical examination (with measurement of $\mathrm{HC}$, length, and weight; assessment of gestational age [and examination for neurologic abnormalities and dysmorphic features

2. Laboratory testing to detect Zika virus

3. Head ultrasonography

4. Standard newborn hearing assessment

5. Additional investigations if both laboratory confirmed infection with clinical disease

Whom to test

Which tests to be done

Follow-up plan
1. Newborns born to mothers with confirmed Zika Virus infection

2. New-born with clinical findings/ neuroimaging findings suggestive of Zika infection with or without microcephaly or with or without the mother being positive

1. Serum for Zika virus rRT-PCR

2. Serum Zika virus IgM ELISA

1. Monthly for at least the first six months after birth:

Monitoring growth parameters, including head circumference

Monitoring development using a standardized, validated developmental screening tool

Providing routine immunizations

Providing anticipatory guidance, psychosocial support, and ensuring infants receive necessary testing and consultations

2. If not performed during the birth hospitalization:

Auditory brainstem response testing within one month

Comprehensive ophthalmologic examination should be performed within one month after birth

Neurologist evaluation within one month

3. Monitor:

Infant feedings

Signs of increasing intracranial pressure (eg, increasing head circumference, irritability, or vomiting)

\section{Appendix 1}

\section{Triple Layer Packing}

1. Primary Container:

- Sterile vial -Use MICROPORE to seal the lid

- Cover vial with cotton or tissue paper

2. Secondary container: Zip lock cover

3. Tertiary container:

- Thermocol box lined with dry ice(ideal)

- Unavailaibility of Dry Ice:Ice packs(4 to 6) to line the thermocol box in order to keep the sample at $2-8{ }^{\circ} \mathrm{C}$

\section{Appendix 2}

\section{Sample Collection Form}


DEPARTMENT OF MICROBIOLOGY

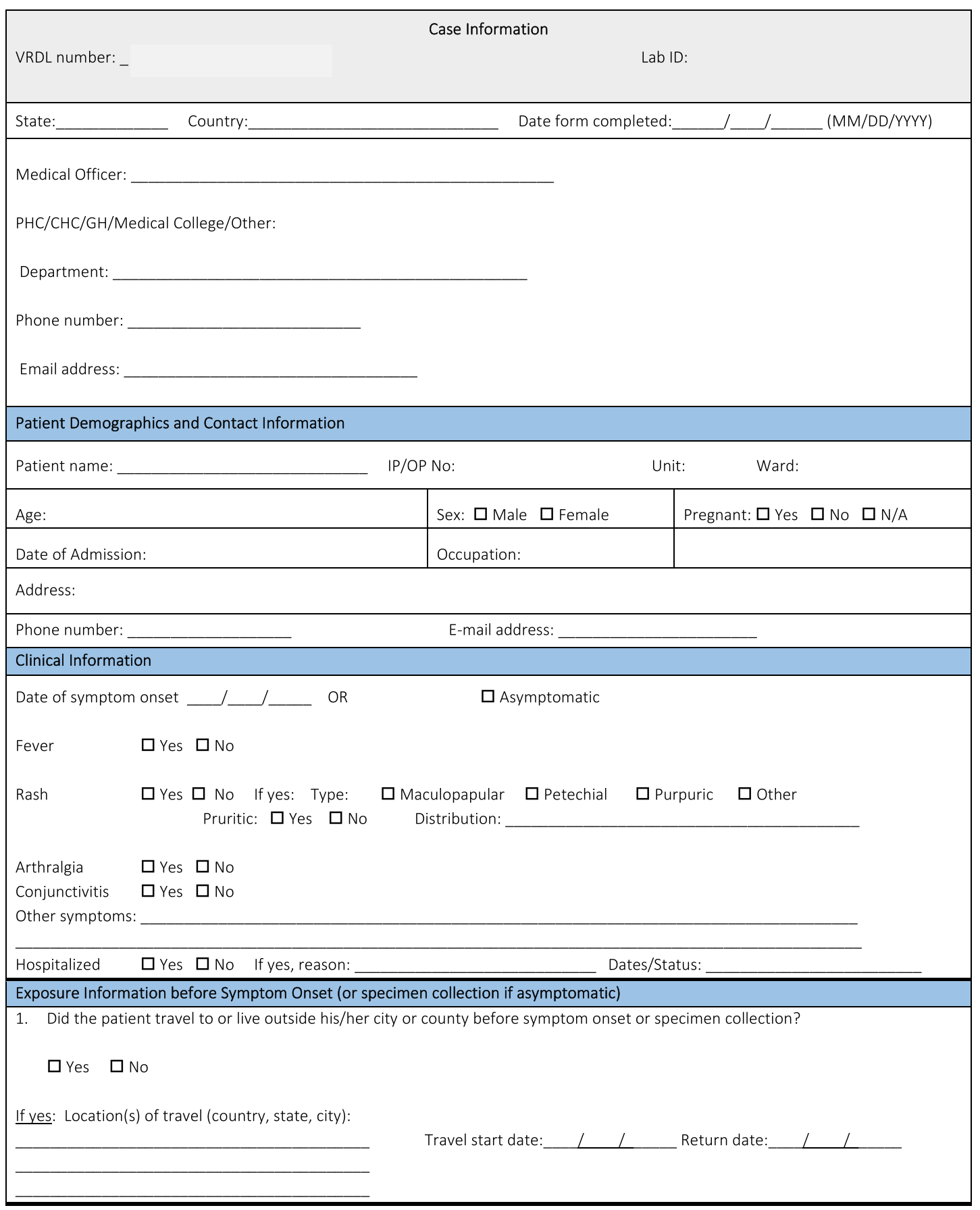

\section{References}

1. American College of Obstetricians and Gynecologists. Practice advisory interim guidance for care of obstetric patients during a
Zika virus outbreak. Reproductive counseling. http://www.acog. org/About-ACOG/News-Room/Practice-Advisories/PracticeAdvisory-Interim-Guidance-for-Care-of-Obstetric-Patients-Duringa-Zika-Virus-Outbreak\#counseling. Accessed 21 Oct 2016. 
2. Paixao ES, Barreto F, da Gloria TM, da Conceicao NCM, Rodrigues LC. History, epidemiology, and clinical manifestations of Zika: a systematic review. Am J Public Health. 2016;106(4):606-12.

3. Centers for Disease Control and Prevention. Zika virus: Transmission. http://www.cdc.gov/zika/transmission/index.html. Accessed 03 Feb 2016.

4. Singh R, Gupta V, Malhotra B, et al. Cluster containment strategy: addressing Zika virus outbreak in Rajasthan, India. BMJ Glob Health. 2019;4(5):e001383. https://doi.org/10.1136/bmjgh2018-001383.

5. https://www.bbc.com/news/world-asia-india59173479\#: :text= At $\% 20$ least $\% 2089 \% 20$ people $\% 2$ C $\% 20$ including,in $\% 20$ cases $\%$ 20in\%20the\%20district.

6. Brasil P, Calvet GA, Siqueira AM, Wakimoto M, de Sequeira PC, Nobre A, et al. Zika virus outbreak in Rio de Janeiro, Brazil: clinical characterization, epidemiological and virological aspects. PLoS Negl Trop Dis. 2016;10(4): e0004636. https://doi.org/10. 1371/journal.pntd.0004636.

7. World Health Organization. Zika virus disease: interim case definitions. World Health Organization. https://apps.who.int/iris/ handle/10665/204381 (2016).

8. Brasil P, Vasconcelos Z, Kerin T, et al. Zika virus vertical transmission in children with confirmed antenatal exposure. Nat Commun. 2020;11:3510.

9. Pomar L, Vouga M, Lambert V, et al. Maternal-fetal transmission and adverse perinatal outcomes in pregnant women infected with Zika virus: prospective cohort study in French Guiana. BMJ. 2018;363:k4431.

10. Brasil P, Pereira JP Jr, Moreira ME, et al. Zika virus infection in pregnant women in Rio de Janeiro. $\mathrm{N}$ Engl $\mathrm{J}$ Med. 2016;375:2321.

11 Shapiro-Mendoza CK, Rice ME, Galang RR, et al. Pregnancy outcomes after maternal Zika virus infection during pregnancy: U.S. Territories, January 1, 2016-April 25, 2017. MMWR Morb Mortal Wkly Rep. 2017;66:615.

12. Rice ME, Galang RR, Roth NM, et al. Vital signs: Zika-associated birth defects and neurodevelopmental abnormalities possibly associated with congenital Zika virus infection: US territories and freely associated states, 2018. MMWR Morb Mortal Wkly Rep. 2018;67:858.

13. Cauchemez S, Besnard M, Bompard P, et al. Association between Zika virus and microcephaly in French Polynesia, 2013-15: a retrospective study. Lancet. 2016;387:2125.

14. World Health Organization. Assessment of infants with microcephaly in the context of Zika virus: Interim guidance, 25 February 2016. http://apps.who.int/iris/bitstream/10665/204475/ 1/WHO_ZIKV_MOC_16.3_eng.pdf. Accessed 25 Feb 2016.
15. Centers for Disease Control and Prevention. Congenital Microcephaly Case Definitions. http://www.cdc.gov/zika/public-healthpartners/microcephaly-case-definitions.html. Accessed 04 April 2016.

16. Society for Maternal-Fetal Medicine (SMFM) Publications Committee. Ultrasound screening for fetal microcephaly following Zika virus exposure. Am J Obstet Gynecol 2016; 214:B2.

17. Sanz Cortes M, Rivera AM, Yepez M, et al. Clinical assessment and brain findings in a cohort of mothers, fetuses and infants infected with ZIKA virus. Am J Obstet Gynecol. 2018;218:440.e1.

18. Pereira JP Jr, Nielsen-Saines K, Sperling J, et al. Association of prenatal ultrasonographic findings with adverse neonatal outcomes among pregnant women with Zika virus infection in Brazil. JAMA Netw Open. 2018;1:e186529.

19. de Oliveira AS, Aguar RS, Maria RM, Arruda MB, de Oliveira F, Clementino RST, et al. Congenital Zika virus Infection Beyond neonatal microcephaly. JAMA Neurol. 2016;73(12):1407-16. https://doi.org/10.1001/jamaneurol.2016.3720.

20. Cooper HJ, Iwamoto M, Lash M, et al. Maternal Zika virus infection: association with small-for-gestational-age neonates and preterm birth. Obstet Gynecol. 2019;134:1197.

21. Orofino DHG, Passos SRL, de Oliveira RVC, et al. Cardiac findings in infants with in utero exposure to Zika virus- a cross sectional study. PLoS Negl Trop Dis. 2018;12:e0006362.

22. Hoen B, Schaub B, Funk AL, et al. Pregnancy outcomes after ZIKV infection in French territories in the Americas. N Engl J Med. 2018;378:985.

23. Pereira JP, Maykin MM, Vasconcelos Z, et al. The role of amniocentesis in the diagnosis of congenital Zika syndrome. Clin Infect Dis. 2019;69:713.

24. Centers for Disease Control and Prevention. Zika virus: Collection and submission of fetal tissues for Zika virus testing. http:// www.cdc.gov/zika/pdfs/collection-submission-fetal-tissues-zikatesting.pdf. Accessed 26 Aug 2016.

25. Moore CA, Staples JE, Dobyns WB, et al. Characterizing the pattern of anomalies in congenital Zika syndrome for pediatric clinicians. JAMA Pediatr. 2017;171:288.

26. World Health Organization. Pregnancy management in the context of Zika virus: Interim guidance, 2 March 2016. http://apps. who.int/iris/bitstream/10665/204520/1/WHO_ZIKV_MOC_16.2_ eng.pdf. Accessed 03 March 2016.

27. https://main.mohfw.gov.in/media/disease-alerts/national-guidelineszika-virus-disease/action-plan-managing-zika-virus-disease.

Publisher's Note Springer Nature remains neutral with regard to jurisdictional claims in published maps and institutional affiliations. 